\title{
Original
}

\section{Ordinary Autonomic Unbalance Can Reflect Diagnosis of Neurally Mediated Reflex Syncope}

\author{
Yoshimi Onishi, Yoshino MinOuRa, Akinori OchI, \\ Kouichirou InOKUChI, Yuta ChIBA, Shirou KawasaKi, \\ Yumi Munetsugu, Yoshimasa Onuma, Miwa Kikuchi, \\ Tatsuya OnUki, Hiroyuki Ito, Fumito Miyoshi, \\ Norikazu Watanabe, Taro Adachi, Taku Asano, \\ Kaoru TANNO and Youichi KoBAYASHI
}

\begin{abstract}
Background: In the present study we investigated autonomic dysfunction using hemodynamics and analysis of heart rate variability (HRV) following ambulatory blood pressure monitoring (APBM) in patients with neurally mediated reflex syncope (NMRS). In addition, we evaluated the usefulness of ABPM for diagnosing NMRS. Methods: In all, 88 consecutive patients with syncope and 12 controls (Group C) were subjected to a head-up tilt (HUT) test $\left(80^{\circ}, 30 \mathrm{~min}\right.$ ). If no syncope or presyncope occurred, the HUT test was repeated in the patient group following drug loading (ATP, isoproterenol, and/or isosorbide dinitrate). Results : Forty patients had a positive HUT test, with or without drug loading (Group P) ; the HUT test was negative in 48 patients, even after drug loading. Average daytime systolic and diastolic blood pressure (SBP and DBP, respectively) was significantly lower in Group $\mathrm{P}$ than in Group $\mathrm{C}(P=0.042$ and $P=0.047$, respectively $)$. The average standard deviation of SBP at night $\left(\mathrm{SD}-\mathrm{SBP}_{\mathrm{Night}}\right)$ was significantly higher in Group $\mathrm{P}$ than in Group $\mathrm{C}(P=0.004)$. HRV analysis revealed a significantly higher daytime high-frequency component in Group $\mathrm{P}$ than in Group $\mathrm{C}$ $(P=0.041)$. Conclusion: The results of the present study suggest that lower daytime blood pressure and a larger $\mathrm{SD}-\mathrm{SBP}_{\mathrm{Night}}$, as determined by $\mathrm{ABPM}$, are associated with vagal nerve hyperactivity and sympathetic hypoactivity in patients with NMRS. Thus, an inadequate circadian rhythm in blood pressure variation, as identified by ABPM, may be useful for the diagnosis of NMRS.
\end{abstract}

Key words : syncope, autonomic dysfunction, hemodynamics, ambulatory blood pressure monitoring

\section{Background}

Neurally mediated reflex syncope (NMRS) is the most common cause of syncope. Previous studies suggest that hyperactivity of the sympathetic nervous system and the subsequent vagal reflex trigger NMRS, but there is still much that remains unknown about autonomic function in patients with NMRS. Kamiya et al reported that there was an increase in vagal tone before 
syncope occurred in a group of subjects who had a positive head-up tilt (HUT) test ${ }^{1)}$. In other studies, Kouakam et al reported that the sympathetic response was decreased after tilting in a HUT test-positive group ${ }^{2)}$ and Kikushima et al reported that epinephrine was elevated prior to the onset of syncope in NMRS patients ${ }^{3)}$. Others have reported an association between the occurrence of syncope and autonomic dysfunction in NMRS patients ${ }^{4-10}$.

Although those prior studies reported autonomic dysfunction during the HUT test, and no significant heart rate variability (HRV) over a 24-h period has been reported in NMRS patients ${ }^{11)}$, many studies have described the usefulness of the HUT test in the diagnosis of NMRS ${ }^{12-15)}$. However, the HUT test does not always induce syncope or presyncope. In the clinical setting, a reasonable number of patients are diagnosed with NMRS based on inferences from their medical history, even if NMRS is not induced by the HUT test.

In the present study we tested the hypothesis that NMRS patients exhibit autonomic dysfunction on a daily basis without syncope. We identified the characteristics of autonomic function in NMRS patients using hemodynamics from ambulatory blood pressure monitoring (APBM) and analysis of heart rate variability (HRV). Further, we investigated the usefulness of ABPM parameters in making a diagnosis of NMRS.

\section{Methods}

\section{Subjects}

We considered all the patients who underwent HUT and ABPM for evaluation of syncope at Showa University Hospital from July 2011 to April 2013. Patients with basal disease related to autonomic dysfunction were excluded from the study. We also considered 12 healthy cases with normal physical examination who underwent ABPM that did not have any episode of syncope in the past as the control group.

\section{Head-Up Tilt Testing}

The HUT test was performed in patients using a Taskforce Monitor (CNSystems Medizintechnik AG, Graz, Austria) within 60 days of the syncope event. The HUT test required that patients stay standing for $30 \mathrm{~min}$ with their head tilted at an $80^{\circ}$ angle. If no syncope or presyncope occurred within $30 \mathrm{~min}$, the HUT test was performed again $15 \mathrm{~min}$ after drug administration. For drug loading, patients were administered ATP $(0.1-0.2 \mathrm{mg} / \mathrm{kg})$, isoproterenol $(0.01 \mu \mathrm{g} / \mathrm{kg} \text { per } \mathrm{min})^{16-20)}$, or isosorbide dinitrate $(5 \mathrm{mg})^{21,22)}$. If no syncope or presyncope was induced during the HUT test after administration of these drugs, the patients were deemed to have a negative result on the HUT test. Patients who developed syncope or presyncope with or without drug loading were deemed to have a positive response to the HUT test (Group P).

\section{Ambulatory Blood Pressure Monitoring}

ABPM was conducted using a TM2425 (A\&D Co. Ltd., Tokyo, Japan) or FM-200 (Fukuda Denshi Ltd., Tokyo, Japan) Blood pressure (BP) and heart rate (HR) were measured automatically every $30 \mathrm{~min}$ for $24 \mathrm{~h}$ (48 measurements). BP was measured by the Korotkoff 
microphone method (KM) and oscillometric method (OM) simultaneously; values obtained by the $\mathrm{OM}$ were used only when $\mathrm{BP}$ could not be determined using the KM. Average values were calculated for measured systolic BP (SBP), diastolic BP (DBP), and HR (Ave-SBP, AveDBP, and Ave-HR, respectively), as were the standard deviations for each parameter (SD-SBP, SD-DBP, and SD-HR, respectively). For analysis, all parameters were separated into daytime (0700-2200 hours) and night-time (2200-0700 hours) periods.

\section{Power spectral analysis of $H R V$}

Continuous R-R intervals from 512 samples were used for HRV analysis and fast Fourier transformation (FFT) was performed for every 30 min block. The low-(LF) and high-frequency (HF) components were defined as $0.04 \sim 0.15$ and $0.15 \sim 0.40 \mathrm{~Hz}$, respectively. The LF and $\mathrm{HF}$ components were corrected to normalized units (nu) using the following equations ${ }^{23-25)}$ :

$$
\begin{aligned}
& \mathrm{LF}_{\mathrm{nu}}=\mathrm{LF} /(\mathrm{LF}+\mathrm{HF}) \\
& \mathrm{HF}_{\mathrm{nu}}=\mathrm{HF} /(\mathrm{LF}+\mathrm{HF})
\end{aligned}
$$

Parameters were calculated for the daytime (0700-2200 hours) and night-time (2200-0700 hours) periods.

\section{Statistical analysis}

All analyses were performed using JMP version 10 (SAS Institute Inc, Cary, NC, USA).

Descriptive statistics (Wilcoxon signed-ranks test and the Mann-Whitney $U$-test) were used for data analysis. $P<0.05$ was considered significant, whereas $P$-values between 0.05 and 0.1 were considered marginally so. Data are presented as the mean $\pm \mathrm{SD}$.

\section{Results}

\section{Hemodynamics by $A B P M$}

Of the 152 syncope patients, 58 had basal disease related to autonomic dysfunction (35 had hypertension, 11 had a history of taking antihypertensive drugs for non-hypertensive reasons, eight had atrial fibrillation, two had complete atrioventricular block, and two had diabetes mellitus). Patients in whom diseases other than NMRS were diagnosed by the HUT test were excluded from the study (three had orthostatic hypotension, two had carotid hypersensitivity syndrome, and one had tachycardia syndrome and postural orthostasis). Of the remaining 88 patients, 40 had a positive HUT test (Group P; mean age $46.2 \pm 22.9$ years; 17 men) and 48 had a negative HUT test $(46.8 \pm 18.7$ years $; 34 \mathrm{men})$. The mean age of the control group (Group $\mathrm{C} ; \mathrm{n}=12$; eight men) was $50.3 \pm 17.6$ years.

\section{Ave-SBP, Ave-DBP, Ave-HR}

In Groups $\mathrm{P}$ and $\mathrm{C}$, Ave-SBP, Ave-DBP, and Ave-HR were significantly lower at night than during the day $(P=0.001$ and $P<0.0001$, respectively, for Ave-SBP; $P=0.018$ and $P=0.0003$, respectively, for Ave-DBP ; $P<0.0001$ and $P<0.0001$, respectively, for Ave-HR). The Ave-SBP 


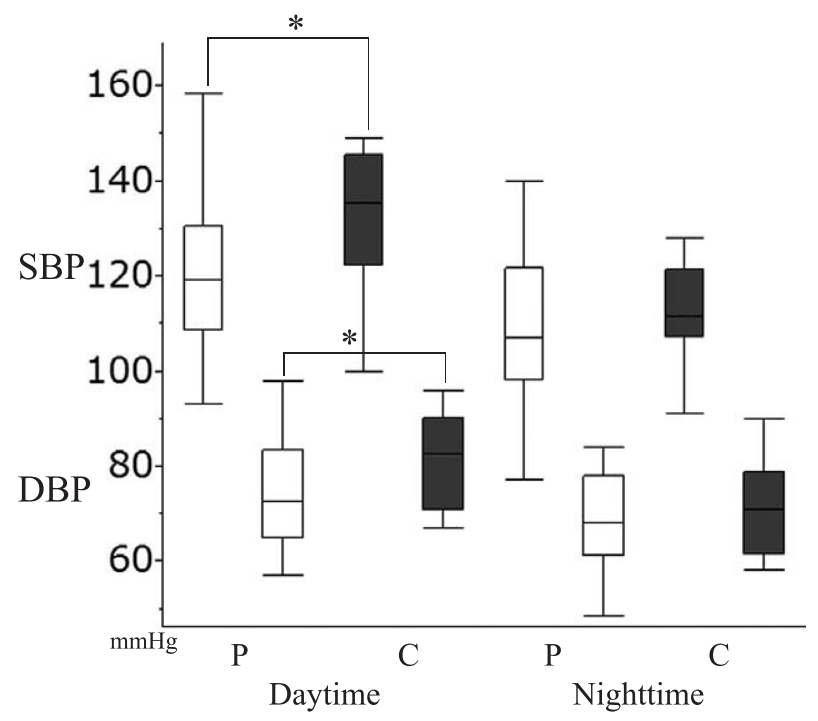

Fig. 1. Transitions in hemodynamics, as determined using ambulatory blood pressure monitoring. Changes in daytime and night-time average systolic blood pressure (Ave-SBP) and average diastolic blood pressure (Ave-DBP) are shown in patients with a positive response on the head-up tilt test (Group P) and in the control group (Group C). Daytime Ave-SBP and Ave-DBP were lower in Group $\mathrm{P}$ than in Group $\mathrm{C}$. The boxes contain the $50 \%$ of values falling between the 25th and 75th percentiles, the horizontal line within the box represents the median value, and the "whiskers" are the lines that extend from the box to the highest and lowest values, excluding the outliers. ${ }^{*} P<0.05$.

Table 1. Hemodynamics parameters determined using ambulatory blood pressure monitoring

\begin{tabular}{|c|c|c|c|c|c|}
\hline & Parameter & & $\begin{array}{l}\text { Group P } \\
(\mathrm{N}=40)\end{array}$ & $\begin{array}{l}\text { Group C } \\
(\mathrm{N}=12)\end{array}$ & $P$ value \\
\hline \multirow{6}{*}{ Ave } & \multirow[t]{2}{*}{$\mathrm{SBP}(\mathrm{mmHg})$} & Day & $121.6 \pm 17.8$ & $132.0 \pm 14.9$ & 0.042 \\
\hline & & Night & $113.1 \pm 25.0$ & $112.2 \pm 10.6$ & NS \\
\hline & \multirow[t]{2}{*}{ DBP $(\mathrm{mmHg})$} & Day & $74.3 \pm 10.7$ & $81.7 \pm 9.9$ & 0.047 \\
\hline & & Night & $71.0 \pm 14.3$ & $71.0 \pm 14.3$ & NS \\
\hline & \multirow[t]{2}{*}{$\mathrm{HR}(/ \mathrm{min})$} & Day & $72.0 \pm 10.4$ & $71.5 \pm 8.3$ & NS \\
\hline & & Night & $59.4 \pm 9.2$ & $57.6 \pm 8.6$ & NS \\
\hline \multirow{6}{*}{ SD } & \multirow[t]{2}{*}{ SBP (mmHg) } & Day & $15.5 \pm 6.05$ & $13.9 \pm 3.1$ & NS \\
\hline & & Night & $12.4 \pm 4.1$ & $9.56 \pm 3.5$ & 0.004 \\
\hline & \multirow[t]{2}{*}{ DBP $(\mathrm{mmHg})$} & Day & $11.83 \pm 3.49$ & $11.56 \pm 3.13$ & NS \\
\hline & & Night & $9.56 \pm 3.01$ & $7.82 \pm 2.64$ & NS \\
\hline & \multirow[t]{2}{*}{$\mathrm{HR}(/ \mathrm{min})$} & Day & $11.44 \pm 4.40$ & $10.17 \pm 4.04$ & NS \\
\hline & & Night & $6.97 \pm 3.80$ & $5.51 \pm 3.41$ & NS \\
\hline
\end{tabular}

Data are the mean \pm SD.

Group $\mathrm{P}$, patients with a positive response on the head-up tilt test; Group C, control group; Ave, average value; SD, standard deviation; SBP, systolic blood pressure; DBP, diastolic blood pressure; HR, heart rate.

in the daytime (Ave-SBP Day $)$ was lower in Group $\mathrm{P}$ than in Group $\mathrm{C}(P=0.042)$. However, there were no significant differences in Ave-SBP during the night (Ave- $\mathrm{SBP}_{\text {Night }}$ ) between the two groups. Ave-DBP in the daytime $\left(\right.$ Ave-DBP $\left.P_{\text {Day }}\right)$ was lower in Group $\mathrm{P}$ than in Group $\mathrm{C}$ $(P=0.047)$, but again there were no significant differences between the two groups in Ave-DBP during the night $\left(\right.$ Ave-DBP $\left.\mathrm{Night}_{\text {ti }}\right)$. Similarly, there were no significant differences in Ave-HR dur-

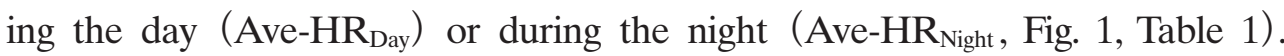




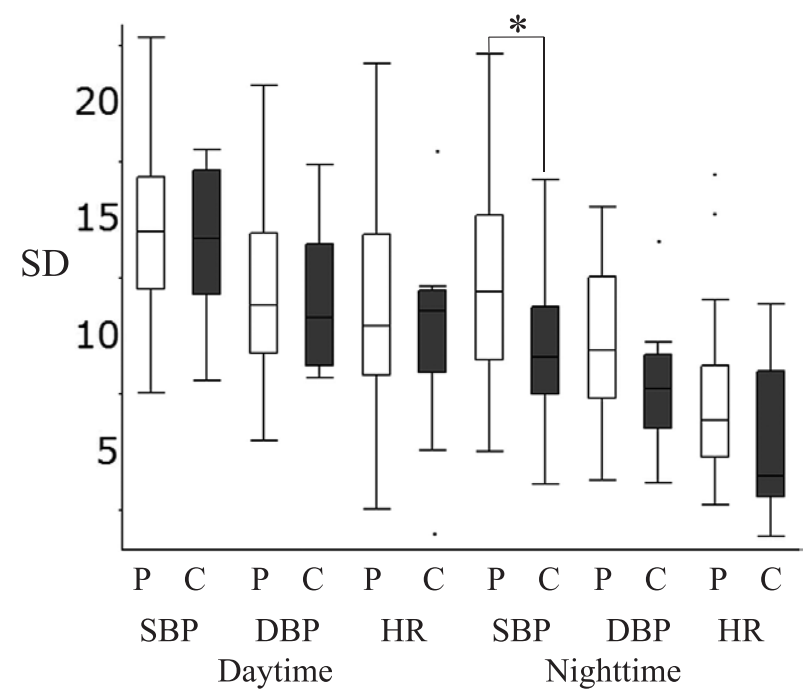

Fig. 2. Transitions in hemodynamics, as determined using ambulatory blood pressure monitoring. Changes in the standard deviation of daytime and night-time systolic blood pressure (SD-SBP), diastolic blood pressure (SD-DBP), and heart rate (SD-HR) are shown in patients with a positive response on the head-up tilt test (Group P) and in the control group (Group C). Night-time SD-SBP was lower in Group $\mathrm{P}$ than in Group $\mathrm{C}$. The boxes contain the $50 \%$ of values falling between the 25 th and 75th percentiles, the horizontal line within the box represents the median value, and the "whiskers" are the lines that extend from the box to the highest and lowest values, excluding the outliers. $* P<0.05$.

\section{$S D-B P$ and $S D-H R$}

In Groups $\mathrm{P}$ and $\mathrm{C}$, SD-SBP, SD-DBP, and SD-HR were lower at night than during the day $(P=0.0038$ and $P<0.0001$, respectively, for SD-SBP; $P=0.0007$ and $P=0.006$, respectively, for SD-DBP ; $P<0.0001$ and $P=0.0004$, respectively, for SD-HR). There were no significant differences between the two groups in daytime SD-SBP $\left(\mathrm{SD}-\mathrm{SBP}_{\text {Day }}\right)$, SD-DBP $\left(\mathrm{SD}-\mathrm{DBP}_{\text {Day }}\right)$, or SD$\mathrm{HR}\left(\mathrm{SD}-\mathrm{HR}_{\text {Day }}\right)$. However, night-time SD-SBP (SD-SBP $\left.\mathrm{Sight}_{\text {f }}\right)$ was significantly higher in Group $\mathrm{P}$ than Group $\mathrm{C}(P=0.004)$. There were no significant differences in night-time SD-DBP (SD$\mathrm{DBP}_{\text {Night }}$ ) or SD-HR (SD-HR $\mathrm{Night}_{\text {S }}$ ) between the two groups (Fig. 2).

\section{Power spectral analysis of $H R V$}

HRV analysis was performed in 25 subjects in total : in 13 of 40 Group $\mathrm{P}$ patients (32.5\% ; mean age $46.2 \pm 22.9$ years; four men) and in all 12 Group $C$ subjects (100\%; mean age $50.3 \pm$ 17.6 years; eight men). The results are described in detail in the following sections.

\section{$L F_{n u}$}

In both Groups $\mathrm{P}$ and $\mathrm{C}, \mathrm{LF}_{\mathrm{nu}}$ decreased significantly during the daytime $(P=0.008$ and $P=$ 0.0004, respectively). However, $\mathrm{LF}_{\mathrm{nu}}$ in the daytime $\left(\mathrm{LF}_{\text {nu-Day }}\right)$ was lower in Group $\mathrm{P}$ than in Group $\mathrm{C}(P=0.041)$. There were no significant differences in $\mathrm{LF}_{\mathrm{nu}}$ during the night between the two groups (Fig. 3, Table 2).

$H F_{n u}$

In both Groups $\mathrm{P}$ and $\mathrm{C}, \mathrm{HF}_{\mathrm{nu}}$ was significantly higher during the night than during the day ( $P=0.008$ and $P=0.004$, respectively). However, $H_{\mathrm{nu}}$ during the day $\left(\mathrm{HF}_{\mathrm{nu}-\mathrm{Day}}\right)$ was significantly higher in Group $\mathrm{P}$ than in Group $\mathrm{C}(P=0.041)$. There were no significant differences in night-time $\mathrm{HF}_{\mathrm{nu}}\left(\mathrm{HF}_{\mathrm{nu}-\mathrm{Night}}\right)$ between the two groups (Fig. 3, Table 2). 


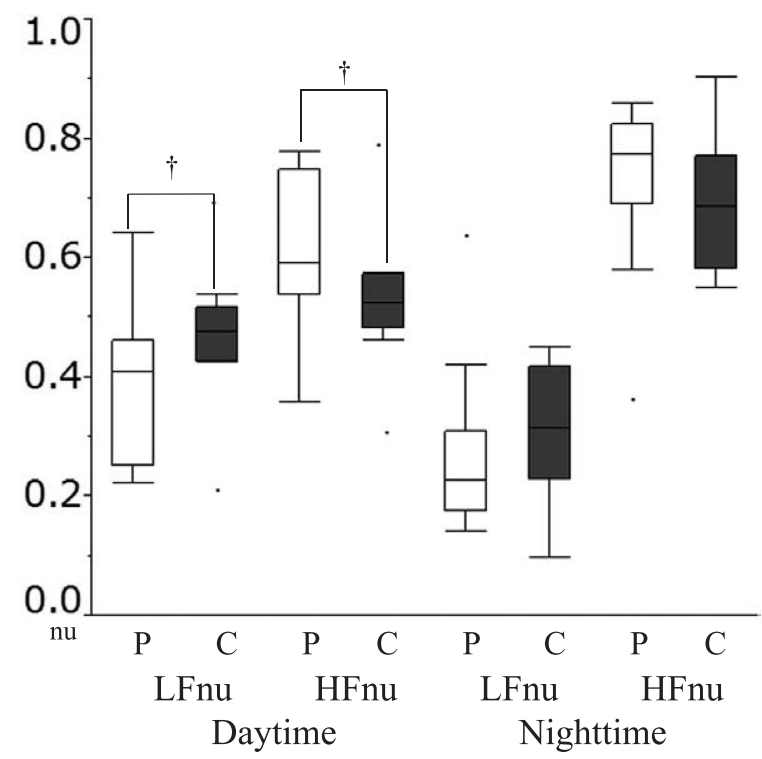

Fig. 3. Transitions in power spectral analysis demonstrated by assessment of heart rate variability. Changes in daytime and night-time normalized low- and highfrequency components ( $\mathrm{LF}_{\mathrm{nu}}$ and $\mathrm{HF}_{\mathrm{nu}}$, respectively) are shown in patients with a positive response on the head-up tilt test (Group P) and in the control group (Group C). Daytime average $\mathrm{HF}_{\mathrm{nu}}$ was higher in Group $\mathrm{P}$ than in Group $\mathrm{C}$, whereas daytime average $\mathrm{LF}_{\text {nu }}$ was lower in Group $\mathrm{P}$ than in Group C. The boxes contain the $50 \%$ of values falling between the 25 th and 75 th percentiles, the horizontal line within the box represents the median value, and the "whiskers" are the lines that extend from the box to the highest and lowest values, excluding the outliers. ${ }^{\dagger} P<0.05$

Table 2. Results of heart rate variability analysis

\begin{tabular}{llccc}
\hline \multicolumn{2}{c}{ Parameter } & $\begin{array}{c}\text { Group P } \\
(\mathrm{N}=13)\end{array}$ & $\begin{array}{c}\text { Group C } \\
(\mathrm{N}=12)\end{array}$ & $P$ value \\
\hline \multirow{2}{*}{ LFnu } & Day & $0.38 \pm 0.14$ & $0.47 \pm 0.11$ & 0.041 \\
& Night & $0.27 \pm 0.14$ & $0.31 \pm 0.11$ & $\mathrm{NS}$ \\
\multirow{2}{*}{ HFnu } & Day & $0.62 \pm 0.14$ & $0.53 \pm 0.11$ & 0.041 \\
& Night & $0.73 \pm 0.14$ & $0.69 \pm 0.11$ & $\mathrm{NS}$ \\
LF / HF & Day & $1.26 \pm 1.15$ & $1.70 \pm 1.26$ & $\mathrm{NS}$ \\
& Night & $0.66 \pm 0.88$ & $0.71 \pm 0.43$ & $\mathrm{NS}$ \\
\hline
\end{tabular}

Data are the mean \pm SD.

Group $\mathrm{P}$, patients with a positive response on the head-up tilt test; Group C, control group ; LF, low frequency (0.04-0.15 $\mathrm{Hz})$; HF, high frequency $(0.15-0.40 \mathrm{~Hz}) ; \mathrm{LF}_{\text {nu }}, \mathrm{LF}$ normalized using the equation $\mathrm{LF} /(\mathrm{LF}+\mathrm{HF}) ; \mathrm{HF}_{\mathrm{nu}}, \mathrm{HF}$ normalized using the equation $\mathrm{HF}_{\mathrm{nu}}=\mathrm{HF} /(\mathrm{LF}+\mathrm{HF})$.

\section{$L F / H F$}

The night-time $\mathrm{LF} / \mathrm{HF}$ ratio $\left(\mathrm{LF} / \mathrm{HF}_{\mathrm{Night}}\right)$ was significantly lower than the daytime $\mathrm{LF} / \mathrm{HF}$ ratio $\left(\mathrm{LF} / \mathrm{HF}_{\text {Day }}\right)$ in both Groups $\mathrm{P}$ and $\mathrm{C}(P=0.042$ and $P=0.0004$, respectively $)$, but there were no significant differences in $\mathrm{LF} / \mathrm{HF}_{\text {Day }}$ and $\mathrm{LF} / \mathrm{HF}_{\mathrm{Night}}$ between the two groups (Fig. 4).

\section{Discussion}

The major findings of the present study are that: (i) Ave-SBP $\mathrm{Day}_{\text {ay }}$ and Ave-DBP $\mathrm{Day}_{\text {Day }}$ were lower in Group $\mathrm{P}$ than Group $\mathrm{C}$; (ii) $\mathrm{SD}_{-\mathrm{SBP}_{\text {Night }}}$ was higher in Group $\mathrm{P}$ than Group $\mathrm{C}$; (iii) $\mathrm{HF}_{\text {nu-Day }}$ was higher in Group $\mathrm{P}$ than Group $\mathrm{C}$; and (iv) there were no significant differences in the $\mathrm{LF} / \mathrm{HF}_{\text {Day }}$ and $\mathrm{LF} / \mathrm{HF}_{\text {Night }}$ ratios between the two groups. These findings suggest that NMRS patients ordinarily exhibit hemodynamic abnormalities that are associated with autonomic 


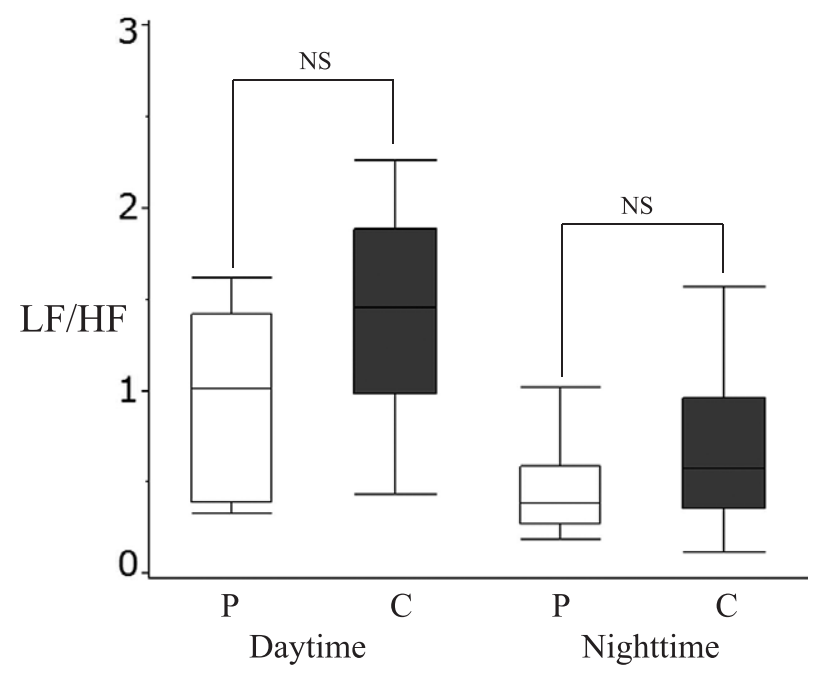

Fig. 4. Transitions in power spectral analysis as evaluated by heart rate variability. Changes in the daytime and night-time ratios of low-frequency (LF) / highfrequency $(\mathrm{HF})$ components in patients with a positive response on the head-up tilt test (Group $\mathrm{P}$ ) and in the control group (Group C). There were no differences in either the daytime or nighttime LF/ HF ratios between the two groups. The boxes contain the $50 \%$ of values falling between the 25th and 75th percentiles, the horizontal line within the box represents the median value, and the "whiskers" are the lines that extend from the box to the highest and lowest values, excluding the outliers.

NS, not significant

dysfunction.

Several studies have demonstrated hemodynamic abnormalities during the HUT test. For example, Wieling et al described correlations between Ave-BP and total peripheral resistance $(\mathrm{TPR})^{26)}$. In addition, those authors concluded that DBP is lower at rest and is unlikely to rise after tilt in patients with a positive HUT test compared with those exhibiting a negative response. Ono et al reported that decreased $\alpha$-adrenergic vascular responses to phenylephrine, an $\alpha_{1}$-adrenergic receptor antagonist, is a factor contributing to $\mathrm{NMRS}^{27)}$. In the present study, we also found that SBP and DBP were significantly higher in patients with NMRS during the HUT test after test drug loading. These results suggest that the onset of syncope during the HUT test can be predicted from the response of BP during the HUT test. In the present study, both daytime and night-time Ave-SBP and Ave-DBP were lower in Group $\mathrm{P}$ than in Group C. These results suggest that patients with syncope have lower BP compared with control, thus leading to lower TPR.

$\mathrm{BP}$ is usually lower at night than during the day, and the $\mathrm{SD}$ of $\mathrm{BP}$ should be smaller at night. However, even though Ave-SBP $\mathrm{Day}_{\text {ay }}$ and Ave-SBP $\mathrm{P}_{\text {Night }}$ in Group $\mathrm{P}$ were smaller than in Group $\mathrm{C}, \mathrm{SD}_{-} \mathrm{SBP}_{\mathrm{Day}}$ and $\mathrm{SD}-\mathrm{SBP}_{\mathrm{Night}}$ in Group $\mathrm{P}$ were large. Narkiewicz et al reported that sympathetic activity is linked to the variability of $\mathrm{BP}^{28)}$. In the present study, the SD-SBP ${ }_{\text {Night }}$ of Group $\mathrm{P}$ was large, but the $\mathrm{LF} / \mathrm{HF}_{\text {Night }}$ ratio of Group $\mathrm{P}$ was small. Vagal nervous hyperactivity and sympathetic hypoactivity of Group $\mathrm{P}$, leading to autonomic imbalance, may be responsible for the larger SD-SBP Night. $_{\text {. }}$

Some studies have investigated HRV during the HUT test in NMRS patients. For example, Kouakam et al reported that increases in LF and the LF/ HF ratio after $5 \mathrm{~min}$ tilt were attenuated in HUT test-positive compared with HUT test-negative groups ${ }^{2)}$. They suggested that this was due to an already increased vagal response immediately after tilt in NMRS patients. Kikushima et al reported that blood concentrations of epinephrine are elevated before the onset of syncope during the HUT test in NMRS patients ${ }^{3)}$. They concluded that an epinephrine surge leading to vagal nerve hyperactivity is one factor in NMRS. In the present study, $\mathrm{HF}_{\text {nu-Day }}$ was 
higher in Group $\mathrm{P}$ than in Group $\mathrm{C}$. This suggests that vagal nerve hyperactivity is linked to the onset of syncope in HUT test-positive patients, which is consistent with the findings reported in the earlier studies.

Piccirillo et al reported that treatment of NMRS patients with tilt training resulted in increased LF and decreased HF components, which was useful for determining the effect on HRV following tilt training ${ }^{29)}$. Elevation of TPR by tilt training may attenuate the instability of hemodynamics, resulting in normalization of autonomic dysfunction.

Future detailed examinations of individual patients may be needed to determine whether autonomic dysfunction itself causes the hemodynamic abnormality in NMRS patients with a positive response to the HUT test, or whether autonomic dysfunction causes syncope or presyncope via other factors. However, the vagal hyperactivity and sympathetic hypoactivity in Group P may have been the cause of the syncope. Therefore, it is possible that autonomic imbalance may be one factor contributing to NMRS.

Drug loading is used to induce syncope during the HUT test in Showa University Hospital. Drug loading during the HUT test is thought to improve the rate of positive responses to the HUT test. However, the number of centers that can perform HUT tests without time restrictions is limited, and drug loading prior to an HUT test takes time. Taking this into consideration, using ABPM to characterize autonomic nervous function in suspected NMRS patients may be more useful and may contribute to the diagnosis of NMRS.

\section{Conclusion}

The results of the present study suggest that lower daytime $\mathrm{BP}$ and larger $\mathrm{SD}-\mathrm{SBP}_{\text {Night, }}$ as determined by ABPM, are associated with vagal nerve hyperactivity and sympathetic hypoactivity in patients with NMRS. Thus, hemodynamic abnormality and an inadequate BP circadian rhythm, as determined by ABPM, may be useful for the diagnosis of NMRS.

\section{Conflict of interest}

The authors have declared no conflict of interest.

\section{References}

1) Kamiya A, Hayano J, Kawada $\mathrm{T}$, et al. Low-frequency oscillation of sympathetic nerve activity decreases during development of tilt-induced syncope preceding sympathetic withdrawal and bradycardia. Am J Physiol Heart Circ Physiol. 2005;289:H1758-H1769.

2) Kouakam C, Lacroix D, Zghal N, et al. Inadequate sympathovagal balance in response to orthostatism in patients with unexplained syncope and a positive head up tilt test. Heart. 1999;82:312-318.

3) Kikushima S, Kobayashi Y, Nakagawa H, et al. Triggering mechanism for neurally mediated syncope induced by head-up tilt test: role of catecholamines and response to propranolol. J Am Coll Cardiol. 1999;33:350-357.

4) Morillo CA, Klein GJ, Jones DL, et al. Time and frequency domain analyses of heart rate variability during orthostatic stress in patients with neurally mediated syncope. Am J Cardiol. 1994;74:1258-1262.

5) Burklow TR, Moak JP, Bailey JJ, et al. Neurally mediated cardiac syncope: autonomic modulation after normal saline infusion. J Am Coll Cardiol. 1999;33:2059-2066.

6) Morillo CA, Eckberg DL, Ellenbogen KA, et al. Vagal and sympathetic mechanisms in patients with orthostatic 
vasovagal syncope. Circulation. 1997;96:2509-2513.

7) Sander-Jensen K, Secher NH, Astrup A, et al. Hypotension induced by passive head-up tilt: endocrine and circulatory mechanisms. Am J Physiol. 1986;251:R742-R748.

8) Goldstein DS, Spanarkel M, Pitterman A, et al. Circulatory control mechanisms in vasodepressor syncope. Am Heart J. 1982;104:1071-1075.

9) Wallin BG, Sundlof G. Sympathetic outflow to muscles during vasovagal syncope. J Auton Nerv Syst. 1982;6:287-291.

10) Sra JS, Murthy V, Natale A, et al. Circulatory and catecholamine changes during head-up tilt testing in neurocardiogenic (vasovagal) syncope. Am J Cardiol. 1994;73:33-37.

11) Sneddon JF, Bashir Y, Murgatroyd FD, et al. Do patients with neurally mediated syncope have augmented vagal tone? Am J Cardiol. 1993;72:1314-1315.

12) Benditt DG, Remole S, Bailin S, et al. Tilt table testing for evaluation of neurally-mediated (cardioneurogenic) syncope: rationale and proposed protocols. Pacing Clin Electrophysiol. 1991;14:1528-1537.

13) Almquist A, Goldenberg IF, Milstein S, et al. Provocation of bradycardia and hypotension by isoproterenol and upright posture in patients with unexplained syncope. $N$ Engl J Med. 1989;320:346-351.

14) Fitzpatrick A, Sutton R. Tilting towards a diagnosis in recurrent unexplained syncope. Lancet. 1989;1:658-660.

15) Kenny RA, Ingram A, Bayliss $\mathrm{J}$, et al. Head-up tilt: a useful test for investigating unexplained syncope. Lancet. 1986;1:1352-1355.

16) Rubin AM, Rials SJ, Marinchak RA, et al. The head-up tilt table test and cardiovascular neurogenic syncope. Am Heart J. 1993;125:476-482.

17) Natale A, Akhtar M, Jazayeri M, et al. Provocation of hypotension during head-up tilt testing in subjects with no history of syncope or presyncope. Circulation. 1995;92:54-58.

18) Sheldon R, Killam S. Methodology of isoproterenol-tilt table testing in patients with syncope. J Am Coll Cardiol. 1992;19:773-779.

19) Kapoor WN, Brant N. Evaluation of syncope by upright tilt testing with isoproterenol. A nonspecific test. Ann Intern Med. 1992;116:358-363.

20) Carlioz R, Graux P, Haye J, et al. Prospective evaluation of high-dose or low-dose isoproterenol upright tilt protocol for unexplained syncope in young adults. Am Heart J. 1997;133:346-352.

21) Raviele A, Gasparini G, Di Pede F, et al. Nitroglycerin infusion during upright tilt: a new test for the diagnosis of vasovagal syncope. Am Heart J. 1994;127:103-111.

22) Del Rosso A, Bartoli P, Bartoletti A, et al. Shortened head-up tilt testing potentiated with sublingual nitroglycerin in patients with unexplained syncope. Am Heart J. 1998;135:564-570.

23) Sayers BM. Analysis of heart rate variability. Ergonomics. 1973;16:17-32.

24) Akselrod S, Gordon D, Ubel FA, et al. Power spectrum analysis of heart rate fluctuation: a quantitative probe of beat-to-beat cardiovascular control. Science. 1981;213:220-222.

25) Pagani M, Lombardi F, Guzzetti S, et al. Power spectral analysis of heart rate and arterial pressure variabilities as a marker of sympatho-vagal interaction in man and conscious dog. Circ Res. 1986;59:178-193.

26) Wieling W, Rozenberg J, Go-Schon IK, et al. Hemodynamic mechanisms underlying prolonged post-faint hypotension. Clin Auton Res. 2011;21:405-413.

27) Ono $\mathrm{T}$, Saitoh H, Atarashi $\mathrm{H}$, et al. Abnormality of alpha-adrenergic vascular response in patients with neurally mediated syncope. Am J Cardiol. 1998;82:438-443.

28) Narkiewicz K, Winnicki M, Schroeder K, et al. Relationship between muscle sympathetic nerve activity and diurnal blood pressure profile. Hypertension. 2002;39:168-172.

29) Piccirillo G, Magri D, Di Carlo S, et al. Power spectral analysis of heart rate variability as a predictive test in choosing the most effective length for tilt-training. Int J Cardiol. 2006;111:59-66.

[Received January 21, 2014 : Accepted January 30, 2014] 